\title{
Construction of a Liquid Membrane Type Benzethonium Ion Sensitive Electrode and its Application to the Potentiometric Titration of Some Anionic Detergents
}

\author{
Masamitsu KATAOKA*, Yoshiteru KOBAYASHI* and Tomihito KAMBARA*
}

\begin{abstract}
Construction of a liquid membrane type benzethonium (benzyldimethyl $[2-[2(p-1,1,3,3$-tetramethylbutylphenoxy) ethoxy]ethyl] ammonium chloride, $\mathrm{C}_{27} \mathrm{H}_{42} \mathrm{ClNO}_{2}$ ) ion sensitive electrode and its application to potentiometric titration of anionic detergents are described. The electrode was prepared by using nitrobenzene extract of benzethonium-tetraphenylborate ion-pair as an ion-exchange membrane. The electrode shows the Nernstian response to benzethonium cation in the concentration range from $10^{-3}$ to $10^{-7} \mathrm{M}$. Electrode potential showed almost constant value in the $\mathrm{pH}$ range from 2 to 12 at the $5 \times 10^{-4} \mathrm{M}$ benzethonium cation concentration. Effects of diverse ions were evaluated and [metal ions did not interfere, but some quaternary onium cations showed strong interference. The present electrode was successfully applied to the potentiometric titrations of some anionic detergents and the results showed good agreement with the familiar Epton method.
\end{abstract}

\section{Introduction}

Nowadays, many liquid membrane type ionselective electrodes sensitive to organic ions were reported. Anionic surfactant ion-selective electrode, i.e., octyl sulfate ${ }^{1)}$, dodecyl sulfate ${ }^{(\sim 4)}$, benzenesulfonate ${ }^{4,5)}$, toluenesulfonate ${ }^{6,7)}$, dodecylbenzenesulfonate $^{(\sim 11)}$, naphthalenesulfonate ${ }^{5}$. ${ }^{12)}$, tetraphenylborate ${ }^{13)}$, bis-(2-ethylhexyl) sulfosuccinate $^{14)}$ ion-selective electrodes were constructed and some of them were applied to the determination of ionic surfactants.

Benzethonium chloride $\left(\mathrm{C}_{27} \mathrm{H}_{42} \mathrm{ClNO}_{2}\right.$, abbreviated as $\mathrm{Benz}^{+} \mathrm{Cl}^{-}$) (Hyamine 1622) is adopted to Japan Industrial Standard ${ }^{15)}$ as the standard reagent for cationic surface-active substance. In this paper, a liquid membrane type benzethonium ion sensitive electrode constructed by using nitrobenzene extract of benzethonium-tetraphenylborate (abbreviated as TPB) ion-pair as an ion-exchange membrane is described. The present electrode was successfully applied to the potentiometric titration of anionic surfactants.

\section{Results and Discussion}

\subsection{Reagent}

\begin{tabular}{|c|c|c|c|}
\hline $\begin{array}{l}\mathrm{Ag} / \mathrm{AgCl} \\
\text { Electrode }\end{array}$ & $\begin{array}{l}\text { Internal } \\
\text { Ref. Soln. } \\
1 \mathrm{mM} \mathrm{Benz}{ }^{+}\end{array}$ & $\begin{array}{l}\text { Liquid Ion-exchanger } \\
1 \mathrm{mM} \mathrm{Benz}{ }^{+}-\mathrm{TPB}^{-} \\
\text {in Nitrobenzene }\end{array}$ & $\begin{array}{l}\text { Sample } \\
\text { Soln. of } \\
\text { Benz }^{+}\end{array}$ \\
\hline
\end{tabular}

\footnotetext{
* Department of Chemistry, Faculty of Science, Hokkaido University (Kita 10, Nishi 8, Kita-ku, Sapporo) Key Words: Benzethonium Chloride, Ion Sensitive Electrode, Potentiometric Titration, Anionic Detergent
}

All the potential measurements were carried out by using a Corning Digital $110 \mathrm{pH}$ Meter equipped with a Hitachi Recorder, 056. A Corning saturated calomel electrode, 476109, was used throughout the study. The composition of the present cell system including the present ion sensitive electrode is as follows. tained from wako Pure Chemicals Co. and a $0.01 \mathrm{M}$ standard solution' was prepared by dissolving $4.6611 \mathrm{~g}$ of reagent in $1 \mathrm{dm}^{3}$ of deionized water. The solution was potentiometrically standardized against $0.01 \mathrm{M}$ silver nitrate solution by the aid of silver eletrode and stored in refrigerator. Sodium tetraphenylborate was obtained from Dojindo Laboratories and the certified purity of reagent was higher than $99.7 \%$. Stock solution of $0.01 \mathrm{M}$ sodium tetraphenylborate was prepared by dissolving $3.4223 \mathrm{~g}$ of the reagent into $1 \mathrm{dm}^{3}$ of water and the solution was stored in refrigerator. The $\mathrm{pH}$ of tetraphenylborate solution was kept to 8.5 by adding Britton-Robinson buffer, because it decomposes gradually in acidic milieu. 
The cell assembly was the same as that described elsewhere ${ }^{16,17)}$. The potential of ion sensitive electrode in the presence of foreign ions is given by the Nikolskii-Eisenman equation ${ }^{18)}$.

$$
\begin{aligned}
E & =E^{\circ}+\frac{2.303 R T}{F} \\
& \times \log \left(a_{\text {Benz }}{ }^{+}+\sum_{\mathbf{j}} K_{\mathbf{j}} \cdot a_{\mathbf{j}}{ }^{1 / \mathbf{z}_{\mathbf{j}}}\right)
\end{aligned}
$$

where $E^{\circ}$ is a constant, $a_{\mathrm{Benz}}^{+}$and $a_{\mathrm{j}}$ are the activities of the object and $j$-th ion, $K_{\mathbf{j}}$ is the selectivity coefficient and $z_{\mathbf{j}}$ is the absolute value of charge on the ion $j$.

\subsection{Preparation of liquid ion-exchange membrane}

The liquid ion-exchange membrane was prepared by the solvent extraction of ion-pair of benzethonium cation and tetraphenylborate anion. To a $10 \mathrm{~cm}^{3}$ of $1.0 \mathrm{mM} \mathrm{Benz} \mathrm{Cl}^{-}$solution in a $100-\mathrm{cm}^{3}$ separatory funnel were added $10 \mathrm{~cm}^{3}$ of $1.0 \mathrm{mM} \mathrm{Na}{ }^{+} \mathrm{TPB}^{-}$solution and $10 \mathrm{~cm}^{3}$ of nitrobenzene. The mixture was shaken for 10 $\mathrm{min}$ and then let stand for $30 \mathrm{~min}$. The organic phase was separated and then anhydrous sodium sulfate was added for the purpose of removing the water. Concentration of the ion-pair in the nitrobenzene extract was $1 \mathrm{mM}$.

\subsection{Selection of counter anion}

Anions of five kinds, i.e., tetraphenylborate, bis-(2-ethylhexyl) sulfosuccinate (EHSS), dodecylbenzenesulfonate(DBS), chromazurol S(Ch. S), and pyrocatechol violet (PV), were used as the counter anion of ion-pair. All the concentration of ion-pair in the ion-exchange membrane is prepared to $1 \mathrm{mM}$. The slope of the calibration curve and their range of straight line are tabulated in Table 1.

Table 1 Selection of the ion-exchange site

\begin{tabular}{l|c|c}
$\begin{array}{l}\text { Ion-exchange } \\
\text { site }\end{array}$ & $\begin{array}{c}\text { Slope } \\
\text { (mV/decade) }\end{array}$ & $\begin{array}{c}\text { Linear7range } \\
\left(-\log \left[\text { Benz }^{+}\right]\right)\end{array}$ \\
\hline EHSS & 58 & $4-6$ \\
DBS & 51 & $4-7$ \\
Ch.S & 53 & $3-5$ \\
PV & 25 & $3-6$ \\
TPB & 59 & $3-7$ \\
\hline
\end{tabular}

EHSS : Bis-(2-ethylhexcyl) sulfosuccinate, DBS : Dodecylbenzenesulfonate, Ch.S : Chromazurol S, PV : Pyrocatechol violet, TPB : Tetraphenylborate

Tetraphenylborate anion was adopted as the counter anion, because of its wide linear range and suitable slope ( $59 \mathrm{mV} /$ activity decade) of calibration curve.

\subsection{Selection of Benz $^{+}-\mathbf{T P B}^{-}$ion-pair concentration in the ion-exchange membrane}

Calibration curves of various ion-pair concentrations are shown in Fig. 1. The electrode constructed with an extract of $0.01 \mathrm{mM}$ ionpair concentration was not suitable, because of

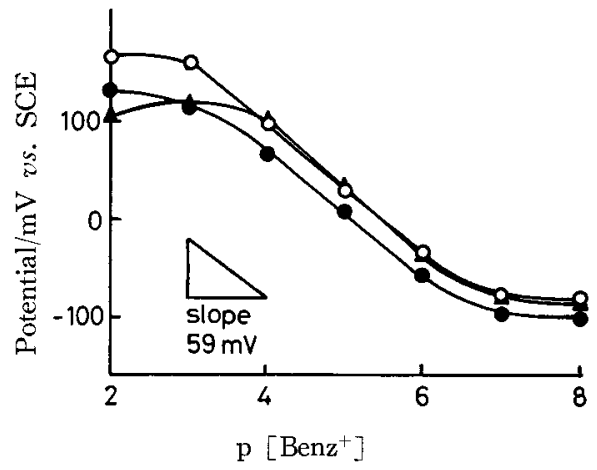

Fig. 1 Selection of $\mathrm{Benz}^{+} \mathrm{Cl}^{-}$ion-pair concentration

Ion-pair concentration in nitrobenzene : - 10, $-\mathrm{O}-1.0,-\boldsymbol{\Delta}-0.1 \mathrm{mM}$. Internal reference electrode : $\mathrm{Ag} / \mathrm{AgCl}$ electrode, Internal reference solution : $1.0 \mathrm{mM} \mathrm{Benz}{ }^{+} \mathrm{Cl}^{-}$, Temp. $18.5^{\circ} \mathrm{C}$

the very poor potential stability. The membrane consisting of $1.0 \mathrm{mM}$ ion-pair was found to be the most suitable.

\subsection{Selection of internal reference elec- trode}

Four kinds of internal reference electrode, i.e., platinum, platinized platinum, silver, and silver-silver chloride electrode, are tested and the results are shown in Fig. 2. Platinum and platinized platinum electrodes showed relatively poor potential stability and their calibration curves are not straight. Silver-silver chloride electrode was adopted because it gave a good calibration curve. As the internal reference solution, a $1.0 \mathrm{mM} \mathrm{Benz}{ }^{+} \mathrm{Cl}^{-}$solution was found to be most suitable.

\subsection{Effect of $\mathrm{pH}$}

Effect of $\mathrm{pH}$ on the EMF of the ion sensitive electrode was evaluated. Concentration of Benz $\mathrm{z}^{+}$ $\mathrm{Cl}^{-}$in sample solution was $5 \mu \mathrm{M}$ and $0.5 \mathrm{mM}$. The total ionic strength was kept at $0.1 \mathrm{M}$ by adding sodium chloride and $\mathrm{pH}$ was adjusted 


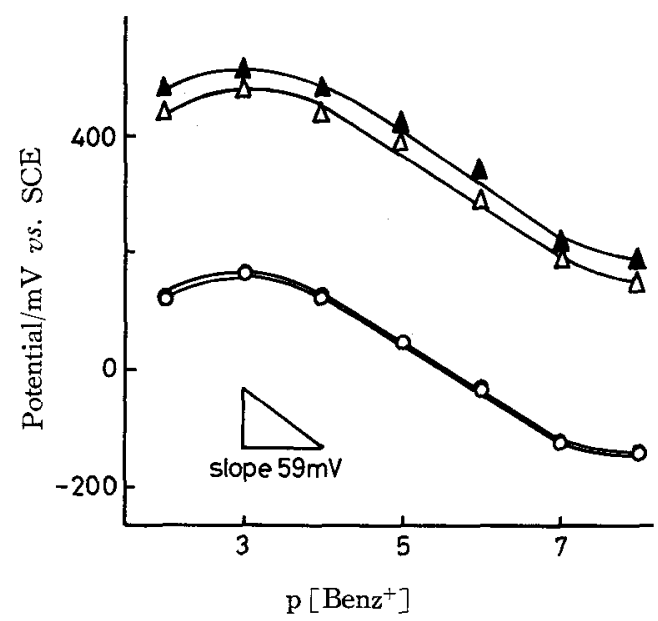

Fig. 2 Selection of internal reference electrode

Internal reference electrode : $-\mathrm{-}-\mathrm{Ag} / \mathrm{AgCl}$, $-\mathrm{O}-\mathrm{Ag},-\boldsymbol{\Delta}-\mathrm{Pt},-\Delta-\mathrm{Pt}-\mathrm{Pt}$ electrode,

Ion-pair concentration : $1.0 \mathrm{mM}$, Temp. $18.5^{\circ} \mathrm{C}$

by adding $0.1 \mathrm{M}$ hydrochloric acid or sodium hydroxide containing the same concentration of object ion. As shown in Fig. 3, the EMF of the present cell was independent of $\mathrm{pH}$ from 2 to 11 for the both levels of benzethonium ion concentration. As to the potential stability of the present electrode, the potential at $10^{-7} \mathrm{M} \mathrm{Benz}^{+} \mathrm{Cl}^{-}$sample solution was shifted about $+10 \mathrm{mV}$ during $40 \mathrm{~min}$. The reason for this fact seems to be an increase in

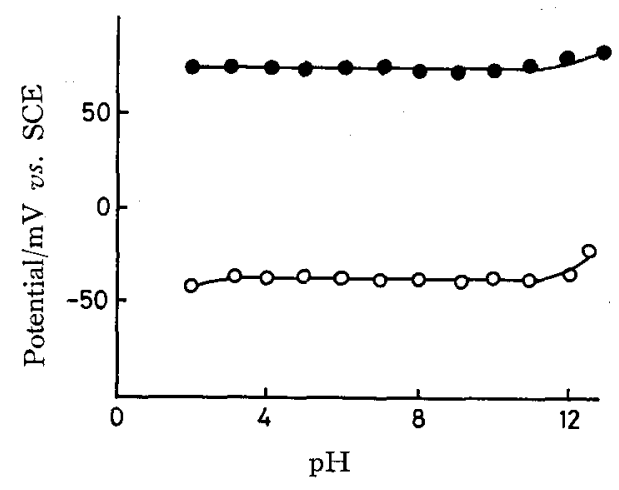

Fig. 3 Electrode response as a fuction of $\mathrm{pH}$

Sample solution : $-0.5 \mathrm{mM},-\mathrm{O}-$ $5 \mu \mathrm{M}$ of $\mathrm{Benz}^{+} \mathrm{Cl}^{-}$containing sodium chloride, hydrochloric acid or sodium hydroxide, Ionic strength : $0.1 \mathrm{M}$ benzethonium ion concentration in the sample solution and/or decrease in $\mathrm{Benz}^{-}-\mathrm{TPB}^{-}$ionpair concentration at the surface of ion-exchange membrane. With benzethonium sample solution higher than $10^{-6} \mathrm{M}$, the EMF was stable during $40 \mathrm{~min}$.

\subsection{Selectivity}

Selectivity coefficients of the benzethonium ion sensitive electrode was evaluated by the familiar mixed solution method ${ }^{19)}$ and the results are tabulated in Table 2. Monovalent and divalent

Table 2 Selectivity coefficient for Benz ${ }^{+}$ ion sensitive electrode

\begin{tabular}{|c|c|c|c|}
\hline Cation & $-\log K_{\mathrm{j}}$ & Cation & $-\log K_{\mathrm{j}}$ \\
\hline $\mathrm{Zeph}^{+}$ & -0.27 & $\mathrm{Na}^{+}$ & 3.64 \\
\hline $\mathrm{CP}^{+}$ & -0.13 & $\mathrm{Fe}^{2+}$ & 3.88 \\
\hline $\mathrm{TMA}^{+}$ & 2.33 & $\mathrm{Fe}^{3+}$ & 4.05 \\
\hline L-Phenylalanine $^{+}$ & 2.88 & $\mathrm{Ca}^{2+}$ & 4.32 \\
\hline L-Cystine ${ }^{+}$ & 3.47 & $\mathrm{Cu}^{2+}$ & 4.55 \\
\hline $\mathrm{NH}_{4}^{+}$ & 3.47 & L-Histidine & 4.65 \\
\hline $\mathrm{K}^{+}$ & 3.61 & & \\
\hline
\end{tabular}

$\mathrm{Zeph}^{+}:$Benzyldimethyltetradecylammonium cation, $\mathrm{CP}^{+}$: Cetylpyridinium cation, $\mathrm{TMA}^{+}$: Tetramethylammonium cation

metal ions do not interfere. The electrode shows, however, only a poor selectivity to some quaternary onium cations.

\subsection{Potentiometric titration}

The present electrode has been successfully applied to potentiometric titration of some anionic surfactants. The titration curves of $\mathrm{Benz}^{+} \mathrm{Cl}^{-}$ solution with $\mathrm{Na}^{+} \mathrm{TPB}^{-}$solution are shown in Fig. 4. Potential jump of the titration curve at the end-point of $1 \mathrm{mM} \mathrm{Benz}{ }^{+} \mathrm{Cl}^{-}$solution with the same concentration of $\mathrm{Na}^{+} \mathrm{TPB}^{-}$solution is almost $400 \mathrm{mV}$. The reason of such a great magnitude of potential jump is that the present electrode is sensitive to $\mathrm{Benz}^{+}$cation as well as $\mathrm{TPB}^{-}$anion. Titration of $10^{-5} \mathrm{M} \mathrm{Benz}^{+}$solution with $\mathrm{TPB}^{-}$solution of the same concentration is feasible. Some anionic detergents are titrated and the results are compared with Epton $\operatorname{method}^{20,21}$. Anionic detergents containing kitchen cleaning materials of "Family" and "Cherina" were also potentiometrically titrated. As shown in Table 3, the method based on the use of present electrode gives results within $2.6 \%$ in relative difference of those obtained 


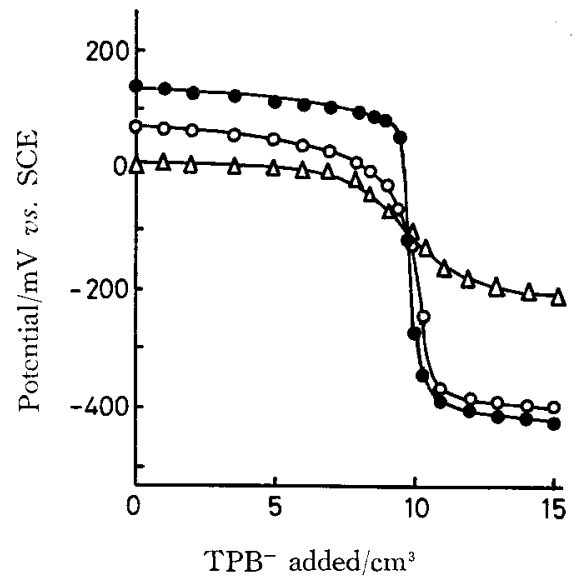

Fig. 4 Potentiometric titration curves of $10 \mathrm{~cm}^{3}$ portions of $\mathrm{Benz} \mathrm{Cl}^{+}$solution with standard $\mathrm{Na}^{+} \mathrm{TPB}^{-}$ solution

- - : Ca. $1 \mathrm{mM} \mathrm{Benz}{ }^{+} \mathrm{Cl}^{-}$titrated with $1.00 \mathrm{mM} \mathrm{Na}{ }^{+} \mathrm{TPB}^{-}, \quad-D-:$ Ca. $0.1 \mathrm{mM}$ Benz ${ }^{+} \mathrm{Cl}^{-}$titrated with $0.100 \mathrm{mM} \mathrm{Na}^{+} \mathrm{TPB}^{-}$, $-\triangle-: \mathrm{Ca} .0 .01 \mathrm{mM} \quad \mathrm{Benz}^{+} \mathrm{Cl}^{-}$titrated with $0.0100 \mathrm{mM} \mathrm{Na}^{+} \mathrm{TPB}^{-}$

Table 3 Comparison of the determinations of anionic detergents

\begin{tabular}{|c|c|c|c|}
\hline \multirow{2}{*}{ Sample } & \multicolumn{2}{|c|}{$\begin{array}{l}10.0 \mathrm{mM} \mathrm{Benz}^{+} \mathrm{Cl}^{-} \\
\text {required } / \mathrm{cm}^{3}\end{array}$} & \multirow{2}{*}{$\begin{array}{c}\text { Relative } \\
\text { difference } \\
(9)\end{array}$} \\
\hline & Present method & $\begin{array}{l}\text { Epton } \\
\text { method }\end{array}$ & \\
\hline EHSS $^{-}$ & $9.06 \pm 0.01$ & $9.25+0.02$ & 2.1 \\
\hline $\mathrm{DBS}^{-}$ & $9.15 \pm 0.03$ & $9.22 \pm 0.03$ & 0.8 \\
\hline $\mathrm{DS}^{-}$ & $9.94 \pm 0.01$ & $9.95 \pm 0.02$ & 0.1 \\
\hline Family $^{a}$ & $9.45 \pm 0.01$ & $9.45 \pm 0.02$ & 0 \\
\hline Cherina $^{b}$ & $12.07 \pm 0.03$ & $12.39 \pm 0.02$ & 2.6 \\
\hline
\end{tabular}

EHSS : Bis-(2-ethylhexcyl) sulfosuccinate, DBS : Dodecylbenzenesulfonate, DS : Dodecyl sulfate, a : Kao Soap Co., diluted 40 fold, b : Kao Soap Co., diluted 50 fold. Number of titrations was five by Epton method.

\section{References:}

1) T. Fuiinaga, S. Okazaki and H. Freiser, Anal. Chem. 64, 1842 (1974).

2) C. Gavach and C. Bertrand, Anal. Chim. Acta 55, 385 (1971).

3) B.J. Birch and D.E. Clarke, Anal. Chim. Acta 61, 159 (1972).

4) B.J. Birch and D.E. Clarke, Anal. Chim. Acta 67, 387 (1973).

5) N. Ishibashi, H. Kohara and K. Horinouchi, Talanta 20, 867 (1973).

6) O.D. Bonner and D.C. Lunney, J. Phys. Chem. 70, 1140 (1966).

7) C.J. Coetzee and H. Freiser, Anal. Chem. 41, 1128 (1969).

8) M. Kataoka and T. Kambara, Bunseki Kagaku 23, 1081 (1974).

9) M. Kataoka and T. Kambara, Denki Kagaku 43, 209 (1975).

10) N. Ishibashi and H. Kohara, Bunseki Kagaku 21, 100 (1972).

11) T. Kobayashi, M. Kataoka and T. Kambara, Talanta 27, 253 (1980).

12) N. Ishibashi, A. Jyo and K. Matsumoto, Chem. Lett. 1973, 1297.

13) M. Kataoka, M. Kudoh and T. Kambara, Denki Kagaku 46, 548 (1978).

14) M. Kataoka, S. Ueda and T. Kambara, Nippon Kagaku Kaishi 1980, 1520.

15) JIS K 3362-1978, Testing Methods for Synthetic Detergent.

16) M. Kataoka and T. Kambara, Denki Kagaku 43, 654 (1975).

17) M. Kataoka and T. Kambara, J. Electroanal. Chem. 73, 279 (1976).

18) G. Eisenman, "Glass Electrode for Hydrogen and Other Cations", Marcel Dekker, New York, 1967.

19) K. Srinivasan and G.A. Rechnitz, Anal. Chem. 41, 1203 (1969).

20) S.R. Epton, Nature 160, 796 (1947).

21) S.R. Epton, Trans. Faraday Soc. 44, 226 (1948).

(Received Mar. 15, 1982; Accepted Jul. 31, 1982) 